\title{
Carbon Fiber-Based Cementitious Composites for Traffic Detection and Weighing In Motion
}

\author{
Dhurgham A. Ghadhban ${ }^{a^{*}}$, Hasan H. Joni (D) ${ }^{b}$, Ali M. Al-Dahawi (D) ${ }^{c}$ \\ ${ }^{a}$ Directorate of Roads and Bridges, Baghdad, Iraq. \\ ${ }^{\mathrm{b}, \mathrm{c}}$ Department of Civil Engineering, University of Technology, Baghdad, Iraq. \\ *Corresponding author Email: 42381@student.uotechnology.edu.iq
}

\section{H I G H L I G H T S}

- Highways may smart to traffic detection by use of self-sensing materials.

- Cementitious sensors with sensitive property to weigh in motion.

- Applied traffic load changes the electrical resistivity of sensors through passing.

\section{A R T I C L E I N F O}

Handling editor: Wasan I. Khalil

\section{Keywords:}

CF-Based cementitious composites

Self-sensing

Sensitive property

Vehicle detection

Weigh during motion

\author{
A B S T R A C T
}

\begin{abstract}
New self-sensing cementitious composites embedded in the highway pavement for vehicle detection and weigh during motion is fabricated. Smart carbon fiber (CF) reinforced cement-based materials with high sensitive property are used as sensors. These smart composites may be able to detect the traffic and sense the weight in motion, thanks to their piezoresistive property. Cement-based sensors capability to vehicle detection was investigated in a real field at the University of Technology campus. Findings clarify that the CF-Based cementitious composites provide have a great potential to use as sensors for detect traffic and its composition also it possibly identifies different vehicular axle loadings (weigh during motion).
\end{abstract}

\section{Introduction}

Traffic detection and weighing in motion are essential parts in management of traffic, design and maintenance. Different instrumentation systems are currently used to present traffic information including vehicle counting, vehicular speed and axles' weight or gross weight of vehicles which are obtained from sensors either on roads, over roads or embedded within the pavement. Several types of vehicle detection sensors are used up to now, like piezoelectric, optical, magnetic and video detectors. However, these types have some negative flaws on pavement surface, too expensive to use extensively as well as high maintenance cost [1] or through using new algorithms for image processing obtained from the traditional methods [2] thus the flaws are still in term of vehicle detection.

Advances in materials science and the development of information technology allow using new generations of multifunctional and intelligent cementitious materials as the durable and inexpensive sensor for engineering applications, so that no sensor is required embedded or attached [3-11]. Thus, the use of these cementitious composites eliminates all problems with conventional sensors that make it interesting solution to use for traffic detection systems [12]. Smart cementitious composites are fabricated by adding conductive fillers, such as CF to developed sensors based on the piezo-resistivity principle which variating their electrical resistivity with external loading. It suggests the use of these composites which act as selfsensors relying on change their electrical properties when subjected to external load in vehicle-speed monitoring system [13].

Laboratory work was firstly carried out by Shi and Chung [14] to fabricate concrete reinforced with short in length of carbon fibers to use as sensors for road traffic monitoring and weighing-in-motion. They found that with increased applied stress up to $(1 \mathrm{MPa})$, the electrical resistance of sensors decreases and is independent of speeds of around (55) mph. After that Wei [13] developed a system for detection of vehicular speed based on the sensitive properties of cement-based filled with CFs, also Jian [15] developed a vehicles weighing system using cement filled with CF based composites. The feasibility of self-sensing carbon nanotubes (CNT) filled cement-based materials was investigated by Han et al. [1] they embedded these 
sensors into the pavement. Their findings indicate that these composites present high accurately to detect passing vehicles. Generally, the stress of the wheels on the highway pavement is not very high; therefore a high sensitivity of detectors is helpful and essential for passing vehicle detection. Han et al. [1] reported that among the existing self-sensing cement-based materials, the cement-based sensors with nickel particle have the great sensitivity to vehicles detection. Laboratory work was carried out by Ghadhban et al.[16] to investigate the piezoresistive behaviors of cementitious materials based on measuring the changes in electrical resistivity (ER) with two types of electrically conductive materials CF and steel fiber (SF) to use it for traffic detection where three types of cement-based sensors were evaluated, with CF, SF, or a hybrid of CF and SF, by applying quasi-static and dynamic load cycles after seven days of curing in different load directions reflecting the electrodes and different circuit type connections of the specimens. Test results revealing that the use of CF was the best choice to make more sensitivity to applied loads in terms of the change in ER compared with other types when the applied load was parallel to the electrode direction. The findings also indicated arrangement of specimens as an electric series circuit type was the best setup configuration for traffic detection and weight in motion measurements. In this paper, piezoresistive CF-Based cementitious composites are design and the feasibility for traffic detection and weighing during motion. These smart cementitious-based sensors are embedded into the pathway of the vehicles to set up a self-sensing pavement to examine the feasibility of using it for speed measurement, traffic flow and composition and weighing in motion.

\section{Materials and experimental work}

\subsection{Materials}

The mixtures that were fabricated in this work consist of common ingredients such as ordinary Portland cement (PC) (similar to ASTM Type I), which is manufactured in Iraq and complies the I.Q.S (5), 1984 [17]; to increase the compressive, tensile and flexural strengths of the specimens, fly ash (FA)/ Class-F was used [18], which is us composites[20] ; silica sand used as fine aggregate with a maximum particle size $300 \mu \mathrm{m}$ and its specific gravity ofcompatible with ASTM-C618 (2005) requirements [19] also, it is used to disperse conductive materials within the cementitio 2.6. The sand particle size distribution complies with the Iraqi specification (IQS 45/1984) [21]. Potable water for mixing and super plasticizer as a high performance superplasticizer concrete admixture (HPSCA) with a density of $1.084 \mathrm{Kg} /$ liter were also used in order to reach an acceptable workability. The HPSCA also works as a dispersant agent and helps to compensate for the lack of water required for cement hydration process due to of the adding the conductive fillers [22]. The chemical and physical properties of both PC, FA are illustrated in Table 1. Figure 1 provides the distribution of particle size of silica sand.The electrically conductive material used in this work was carbon fiber (CF) with $12 \mathrm{~mm}$ length and density of $1.7 \mathrm{~g} / \mathrm{cm} 3 \mathrm{also}$; it used to reduce the humidity of specimens where it works to increase the air-dry density of the specimens [23]. Its tensile strength equal to $4200 \mathrm{MPa}$ its elastic modulus was $240 \mathrm{GPa}$. In addition, polyolefin fiber (PE) with a length of $48 \mathrm{~mm}$, a diameter of $0.9 \mathrm{~mm}$ and a specific gravity of 0.9 were used to improve the mechanical properties of the composites produced to apply the stress, despite their impact on reducing the conductive property of the composites because it acts like dielectric materials.

\subsection{Materials proportions and Mixing Method}

The preparations of mixture were (W/CM), (FA/PC) and (aggregate /CM)) 0.27, 1.2 and 0.36, respectively, where CM represents to cementitious materials $(\mathrm{FA}+\mathrm{PC})$. The dosage of $\mathrm{CF}$ was $1 \%$ by volume of mixture. All these utilization rates were decided based on the work carried out by Al-Dahawi et al. [24]. In addition to that, and based Al-Dahawi et al. [24] the proportion of superplasticizer was $0.85 \%$ by volume of mixture to get the same mixtures' workability in mixtures were used at previously mentioned study. The PE fiber was used with a percentage of $0.5 \%$ by the volume of the mixture.

\subsection{Materials proportions and Mixing Method}

The preparations of mixture were (W/CM), (FA/PC) and (aggregate /CM)) 0.27, 1.2 and 0.36, respectively, where CM represents to cementitious materials $(\mathrm{FA}+\mathrm{PC})$. The dosage of $\mathrm{CF}$ was $1 \%$ by volume of mixture. All these utilization rates were decided based on the work carried out by Al-Dahawi et al. [24]. In addition to that, and based Al-Dahawi et al. [24] the proportion of superplasticizer was $0.85 \%$ by volume of mixture to get the same mixtures' workability in mixtures were used at previously mentioned study. The PE fiber was used with a percentage of $0.5 \%$ by the volume of the mixture.

Table 1: Chemical compositions and physical properties of cementitious materials

\begin{tabular}{ccc}
\hline Chemical Composition \% & Cement & Fly Ash \\
SiO2 & $\mathbf{2 1 . 3 3}$ & $\mathbf{5 2 . 2 2}$ \\
\hline $\mathrm{Al} 2 \mathrm{O} 3$ & 3.74 & 16.58 \\
$\mathrm{Fe} 2 \mathrm{O} 3$ & 4.76 & 6.6 \\
$\mathrm{CaO}$ & 62.35 & 7.98 \\
$\mathrm{SO} 3$ & 2.01 & 0.02 \\
ssmentMgO & 3.37 & 2.1 \\
Loss on ignition & 2.07 & 10.36 \\
\hline Physical Properties & & 2.1 \\
\hline Specific Gravity & 3.15 & 295 \\
\hline
\end{tabular}




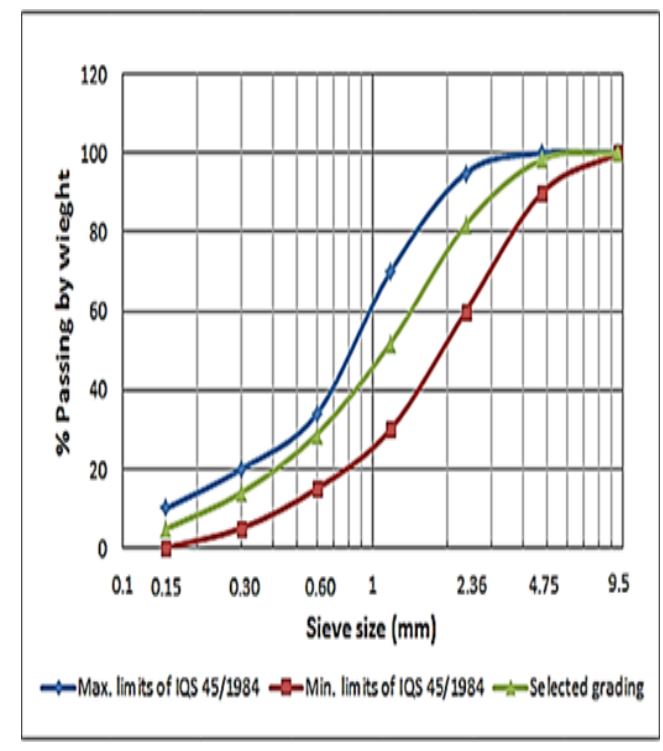

Figure 1: Gradation for fine silica sand

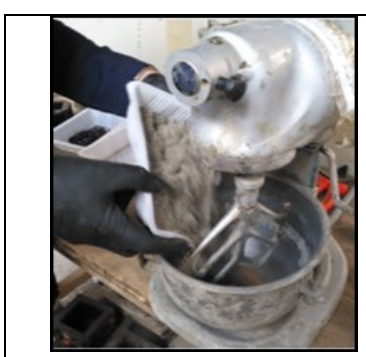

(a) Raw materials in dry condition

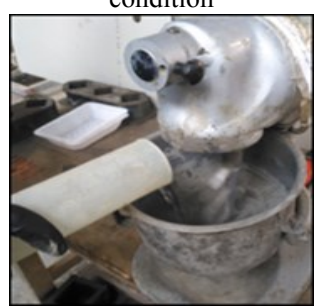

(c) Adding water to the materials

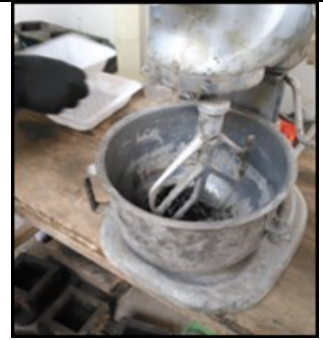

(b) Adding CF and mixing

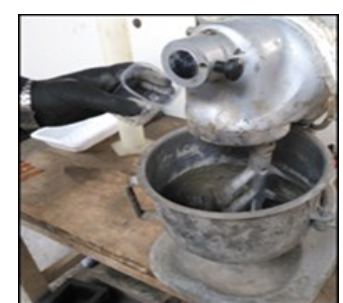

(d) Adding of HPSCA to the mixture
Figure 2: Production of smart cementitious composites mixtures

According to previous studies, the uniform distribution of conductive materials within cementitious systems is crucial for the formation of a continuous electrical network capable of capturing or sensing changes in strain in real-life structures [2527]. Therefore, to gain highest electrical conductivity in specimens without losing mechanical properties, the mixing method that was suggested by Al-Dahawi et al. [28] to mix the micro-scale carbon-based materials was utilized in the present work. This method can be explained as follows, first CFs are mixed with all raw materials (Portland cement, Fly ash and fine silica sand) in dry condition in a mortar mixer 5-liter-capacity for 10 minutes at (100) rpm. The water, then, is added during mixing over 10 seconds. Then, increasing the speed of mixer up to (300) rpm and all amount of the (HPSCA) is added over 30 seconds. The mixing process of all these materials continues for an additional 10 minutes. After that, PE are added. Figure 2 explains these steps of mixing methods.

\subsection{Preparation of Smart Cementitious Composites Sensors}

Four prismatic sensors with dimension of $(100 \times 100 \times 400) \mathrm{mm}$ were used and its preparation started from oiling the internal surfaces of the moulds, where the fresh mixture have been poured in these moulds. The specimens were vibrated to minimize the air bubbles inside them via table vibrator. After pouring of the mixture in the moulds, the pre-prepared brass plate electrodes were placed at a distance of around $2 \mathrm{~cm}$ from the edge of moulds at the tension/compression surface of the sensors with $(20 \mathrm{~mm})$ extra lengths of the electrodes to use it for connecting the specimen with the digital multi-meter, which responsible for measuring the electrical resistance. After the completion of the casting, the specimens were kept in their moulds at $23 \pm 20 \mathrm{C}$ for 24 hours. After 24 hours, the specimens were removed from their moulds and moved into water tanks and kept them until one day before installation, which is 28 days. Twenty-four hours before the installation date, the specimens have been removed from the water tanks and kept in an oven at $60 \mathrm{oC}$ to eliminate the undesired water, which has effects on the ER measurements by polarization [22]. Figure 3 illustrates the preparation of casting and curing process.

\section{Field Test for Cementitious Composites Sensors}

The field test was carried out at the University of Technology campus at the Department of Applied Sciences' gate. The investigation process was limited to monitor one passenger car and one bus that entering and leaving the university at different times of the day. A portable dynamic vehicle weighing system was used to in order to know the weights of axles of the vehicles in motion that pass over the sensors to ensure the efficiency of smart specimens for the lowest applied stresses, which are the weights of axles. Figure 4 shows the setup of the WIM system and Table 1 illustrates the measurement of the axle load of a passenger car and bus.

The installation of the cementitious sensors were fixed into holes using a fast hardening cement mortar and sand with a mixing ratio of 1:3. Figure 5 shows the installation process. Then wires were used to connect the sensors with a digital multimeter connected with a PC by a software program to record the change in the electrical resistancevia direct current (DC) with 2-probe method. The digital multi-meter and PC interface are explained in Figure 6. The smart specimens were arranged as an electric series circuit type, so that each sensor is in the path of the wheel. Figure 7 illustrates the employment of self-sensing specimens for traffic monitoring. 

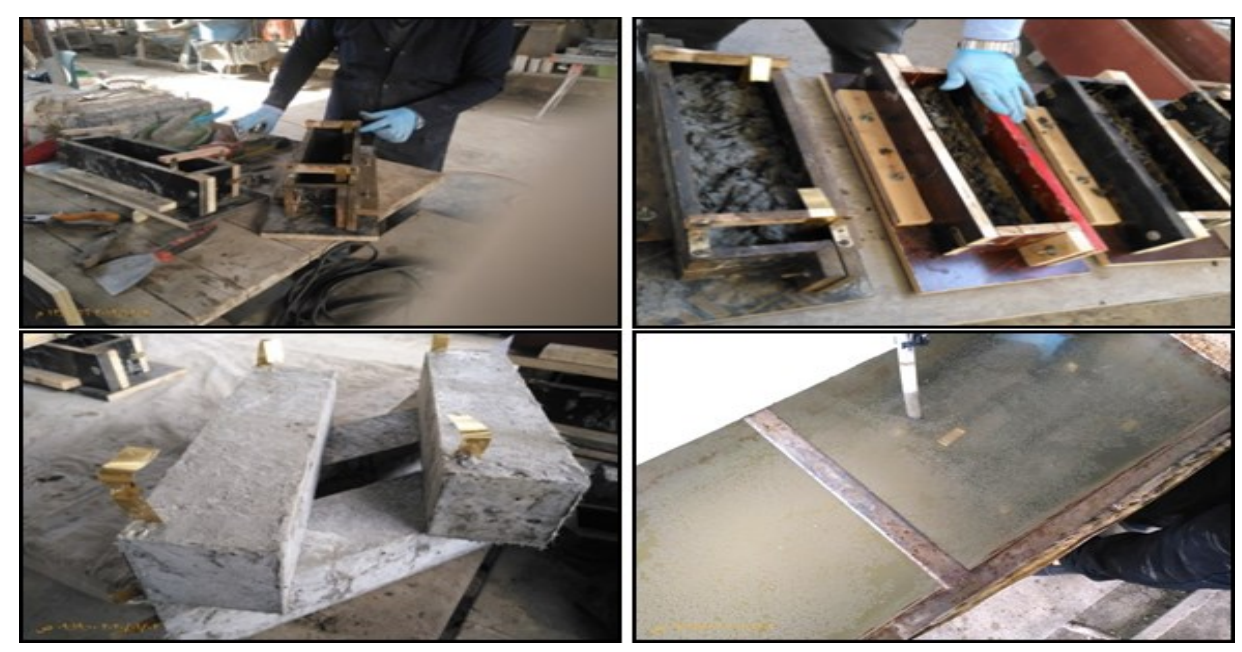

Figure 3: Preparation of smart cementitious composites sensors
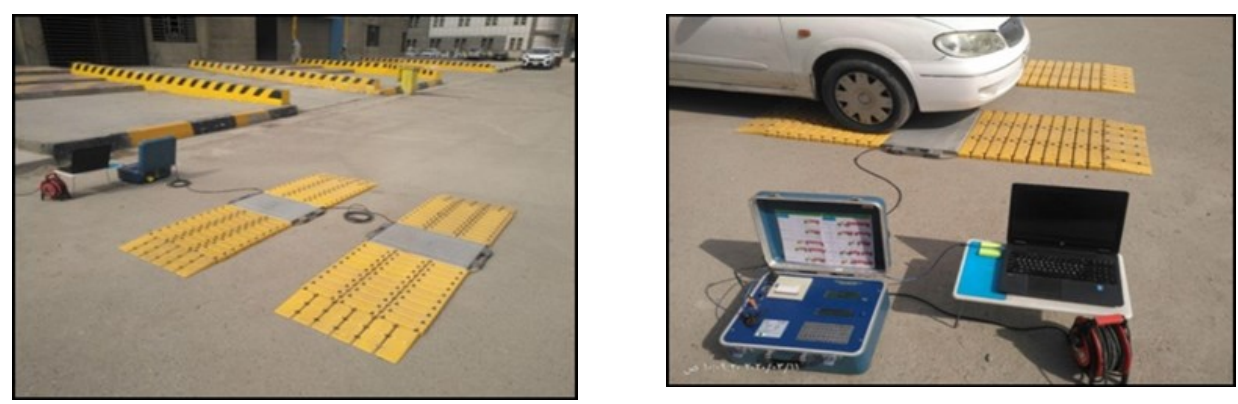

Figure 4: Measurement of axle load in motion by WIM system

\section{Results and Discussion}

Figure 8 shows the changes in the electrical resistance curves o of the cementitious prismatic sensor under both weights of axles that passed over the sensor for two different vehicles detected at 28 days of curing, which corresponds well to the structure of the passing vehicles where figure 8 (a) shows the variations of resistance when passenger vehicle passes over the sensor and figure 8 (b) shows the results when another vehicle (i.e. bus) passes over the CF/cementitious sensors. As shown in Figure 8, axle loads can cause major resistance changes for the samples. Comparing figure 8 (b) with figure $8(\mathrm{a})$, we may also find that the variation amplitude in the electrical resistance of a bus passing over sensors is greater than that of a passenger car, which is due to the heavier axis weight of the bus (i.e. greater applied stress). For instance, the front bus axle load (3100kg), the change in electrical resistance is up to $(0.4 \Omega)$ beside only $(0.1 \Omega)$ for the front passenger car axle load $(800 \mathrm{Kg})$ thus this feature can be exploited to classify the vehicle types based on its axles' weigh.

The sensing mechanism of the cementitious composite sensors as explained by (Han et al., 2012) is the occurrence of changes in the electrical resistance of the sensors when exposed to vehicle loads that followed by changes in the length of the conductive fibers, which leads to changes in the electrical resistance. Also, the insulating mortar thickness can be significantly reduced between adjacent fibres, where the vehicular wheel load caused to change the space at the contact area due to form new electrical tunnels that lead to decrease the contact resistance between CF and mortar. Therefore, the self-sensing property of these cementations results from three electrical resistance changes, the first being changes in the interior resistance of the fibers, the other from changes in contact between the fibers, and the third from changes in contact between carbon fibers and mortar under axle load.

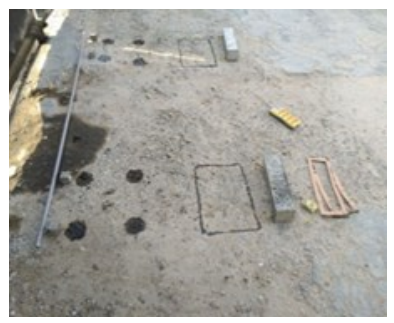

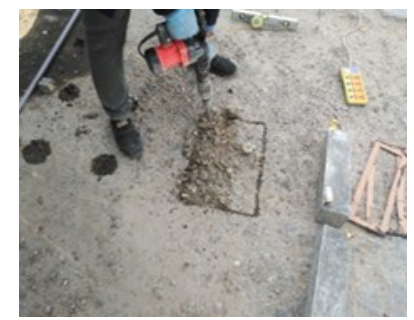

Marking and excavation process

Figure 5: Installation of self-sensing specimens

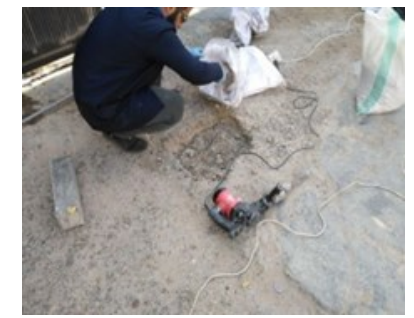



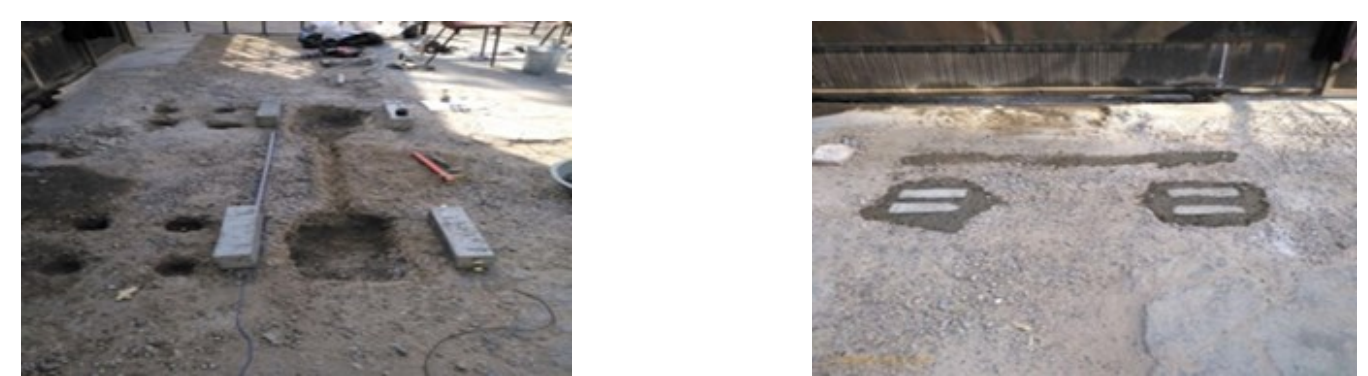

Fixing process of sensors into the holes

Figure 5: Continued

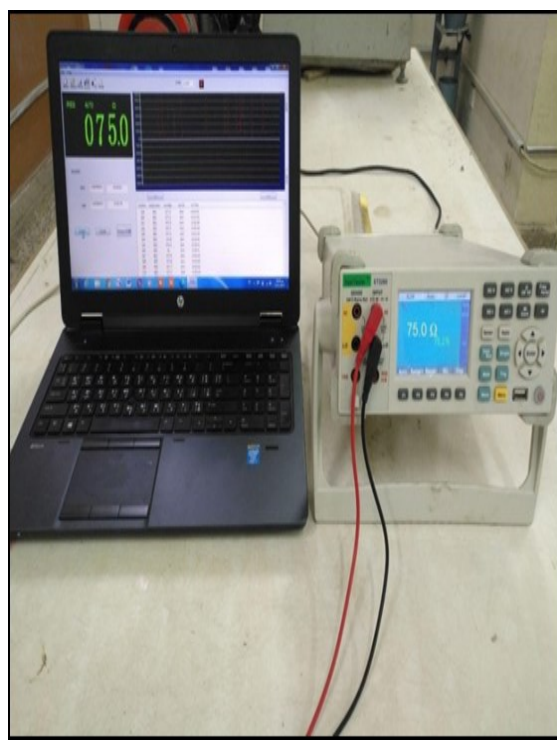

Figure 6:Digital multi-meter with computer interface

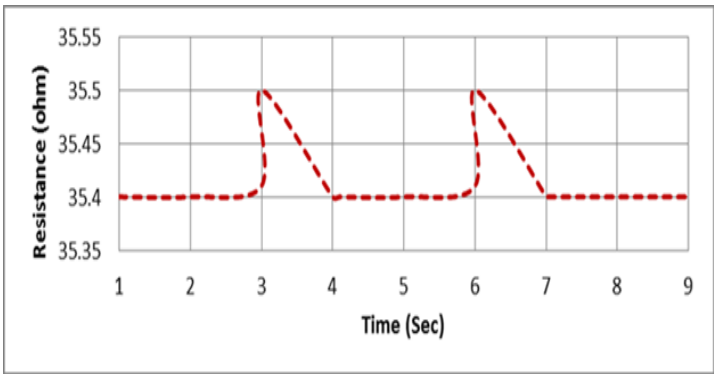

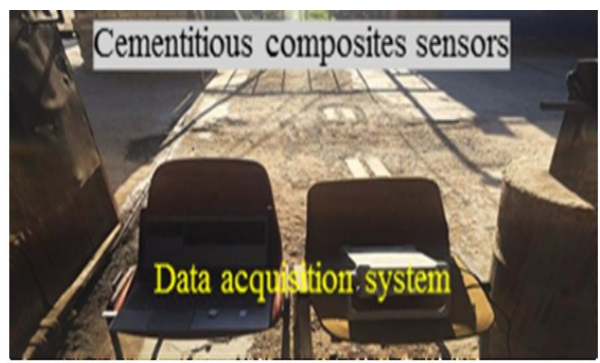

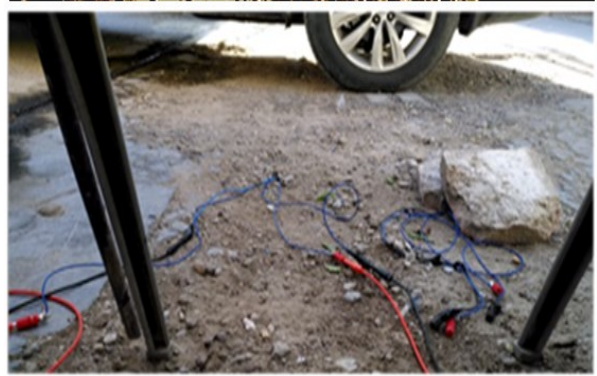

Figure 7:Measurement of axle load in motion by self-sensing specimens

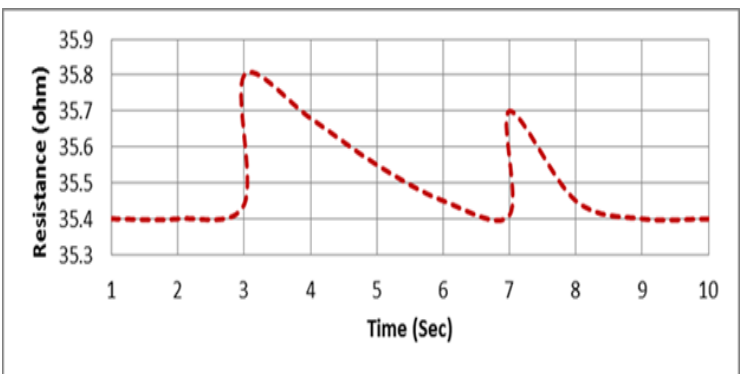

Figure 8: Electrical resistance of prismatic CF-based cementitious composite under different vehicular loading: (a) passenger car (b) bus

Table 2: Chemical compositions and physical properties of cementitious materials

\begin{tabular}{|c|c|c|}
\hline $\begin{array}{l}\text { Chemical Composition \% } \\
\text { SiO2 }\end{array}$ & $\begin{array}{c}\text { Cement } \\
21.33\end{array}$ & $\begin{array}{c}\text { Fly Ash } \\
52.22\end{array}$ \\
\hline $\mathrm{Al} 2 \mathrm{O} 3$ & 3.74 & 16.58 \\
\hline $\mathrm{Fe} 2 \mathrm{O} 3$ & 4.76 & 6.6 \\
\hline $\mathrm{CaO}$ & 62.35 & 7.98 \\
\hline $\mathrm{SO} 3$ & 2.01 & 0.02 \\
\hline ssmentMgO & 3.37 & 2.1 \\
\hline Loss on ignition & 2.07 & 10.36 \\
\hline \multicolumn{3}{|c|}{ Physical Properties } \\
\hline Specific Gravity & 3.15 & 2.1 \\
\hline Specific surface area $(\mathrm{m} 2 / \mathrm{Kg})$ & 394 & 295 \\
\hline
\end{tabular}


Table 3: Vehicle axle weights

\begin{tabular}{cccc}
\hline Vehicle Type & Gross Weight $\mathbf{( K g )}$ & Front Axle $\mathbf{( K g )}$ & Rear Axle (Kg) \\
\hline Passenger car & 1300 & 800 & 500 \\
Bus & 5100 & 3100 & 2000 \\
\hline
\end{tabular}

\section{Conclusions}

This work investigated new self-sensing CF-based cementitious composites for traffic detection and weighing of vehicles during motion based on their piezoresistive property. The field monitoring work shows that these new sensors can detect and provide important traffic data for vehicles such as speed, traffic flow rates, traffic composition with very well performs. In addition, the ability of these smart composites to identify heavy truck loadings during motion normally with less effect on traffic flow. This advantage is due to the effective use of the intrinsic self-sensing CF-based composites. Moreover, these embedded sensors have the advantages of high detection precision, easy installation and maintenance, long service life, and provide a large area of detection. For future work on these smart composites will include the investigations of the self-sensing performance at any highway section contains data including different vehicle speeds, traffic flow rates and heavy trucks with provide control station at any section chosen for analysis purposes data.

\section{Acknowledgment}

The authors would like to thank Civil Engineering Department and Concrete Laboratory for their assistance, the roads and bridges directorate for using the portable dynamic vehicle weighing system.

\section{Author Contribution}

All authors contributed equally to this work.

\section{Funding}

This research received no specific grant from any funding agency in the public, commercial, or not-for-profit sectors.

\section{Data Availability Statement}

The data that support the findings of this study are available on request from the corresponding author.

\section{Conflicts of Interest}

The authors declare that there is no conflict of interest.

\section{References}

[1] B. Han, K. Zhang, X. Yu, E. Kwon, and J. Ou, "Nickel particle-based self-sensing pavement for vehicle detection," Measurement,vol. 44, no. 9, pp. 1645-1650, 2011.

[2] L. J. Sajida and S. Mahmooda, "An Efficient Approach for Detecting and Classifying Moving Vehicles in a Video Based Monitoring System," Engineering and Technology, vol. 38, Part A (2020), No. 60, 2020.

[3] P. Chen and D. J. Chung, "Concrete reinforced concrete as a smart material capable of non-destructive flaw detection,"Smart Materials and Structures, vol. 2, pp. 22-30,1993.

[4] P.W. Chen and D. J. Chung, "Carbon fiber reinforced concrete as an intrinsically smart concrete for damage assessment during dynamic loading," MATERIALS RESEARCH SOCIETY SYMPOSIUM PROCEEDINGS,vol. 360,1994.

[5] P.W. Chen and D. J. Chung, "Concrete as a new strain/stress sensor," Composites Part B: Engineering, vol. 27, no. 1, pp. 11-23, 1996.

[6] P.W. Chen and D. J. Chung, "Carbon fiber reinforced concrete as an intrinsically smart concrete for damage assessment during static and dynamic loading," Materials Journal, vol. 93, no. 4, pp. 341-350, 1996.

[7] X. Fu, D. J. Chung, and C. Research, "Effect of curing age on the self-monitoring behavior of carbon fiber reinforced mortar," Cement and concrete Research,vol. 27, no. 9, pp. 1313-1318, 1997.

[8] X. Fu, E. Ma, D. Chung, W. J. Anderson, and C. research, "Self-monitoring in carbon fiber reinforced mortar by reactance measurement," Cement and concrete Research,vol. 27, no. 6, pp. 845-852, 1997.

[9] X. Fu, W. Lu, and D. J. Chung, "Ozone treatment of carbon fiber for reinforcing cement," Carbon,vol. 36, no. 9, pp. 13371345, 1998.

[10] X. Fu, W. Lu, D. J. Chung, and C. research, "Improving the strain-sensing ability of carbon fiber-reinforced cement by ozone treatment of the fibers," Cement and concrete research,vol. 28, no. 2, pp. 183-187, 1998. 
[11] B. Han, X. Yu, and J. Ou, "Self-sensing concrete in smart structures," Butterworth Heinemann, vol. 18, no. 3, pp. 415,2014 .

[12] A. Monteiro, P. Cachim, P. Costa, and M. Oeser, "Sensitive smart concrete loaded with carbon black nanoparticles for traffic Monitoring," In Fourth Conf. on Smart Monitoring, Assessment and Rehabilitation of Civil Structures (Zurich, Switzerland,), vol. 28, 2017.

[13] W. J. Wei, "A research of the traffic vehicle-speed measuring system based on the pressure-sensitivity of CFRC," Shantou University,2003.

[14] Z.Q. Shi and D. Chung, "Carbon fiber-reinforced concrete for traffic monitoring and weighing in motion," Cement and Concrete Research, vol. 29, no. 3, pp. 435-439, 1999.

[15] H. J. Jian, "Research of the traffic weighting monitoring system based on the pressure-sensitivity of CFRC," Shantou University,2004.

[16] D. A. Ghadhban, H. H. Joni, and A. M. Al-Dahawi, "Smart Cementitious Composites for Road Traffic Monitoring and Weighing in Motion," in IOP Conference Series: Materials Science and Engineering, 2021, vol. 1067, no. 1, p. 012012: IOP Publishing.

[17] Iraqi Standard Specification, No. 5/1984, "Portland Cement," 1984.

[18] S. M. Kamal, J. A. Saeed, A. J. E. Mohammed, and T. Journal, " The Characterization and Modeling the Mechanical Properties of High Strength Concrete (HSC) Modified with Fly Ash (FA)," Engineering and Technology, vol. 38, no. 2A, pp. 173-184, 2020.

[19] Standard specification for coal fly ash and raw or calcined natural pozzolan for use in concrete, ASTM C 618, 2005.

[20] J. Zuo, W. Yao, X. Liu, J. T. Qin, and Evaluation, "Sensing properties of carbon nanotube-carbon fiber/cement nanocomposites," Journal of Testing and Evaluation, vol. 40, no. 5, pp. 838-843, 2012.

[21] Iraqi Standard Specification, No. 45/1984, "Aggregate sieve analysis," 1984.

[22] A. Monteiro, P. Costa, M. Oeser, P. J. S. M. Cachim, and Structures, "Dynamic sensing properties of a multifunctional cement composite with carbon black for traffic monitoring," Smart Materials and Structures,vol. 29, no. 2, p. 025023, 2020.

[23] G. J. E. Salman and T. Journal, "Density and ultrasonic pulse velocity investigation of self-compacting carbon fiberreinforced concrete,"Engineering and Technology, vol. 36, no. 1A, 2018.

[24] A. Al-Dahawi et al., "Electrical percolation threshold of cementitious composites possessing self-sensing functionality incorporating different carbon-based materials," Smart Materials and Structures, vol. 25, no. 10, pp. 1-15, 2016.

[25] B. M. Tyson, R. K. Abu Al-Rub, A. Yazdanbakhsh, and Z. Grasley, "A quantitative method for analyzing the dispersion and agglomeration of nano-particles in composite materials," Composites Part B: Engineering, vol. 42, no. 6, pp. 13951403, 2011.

[26] A. Yazdanbakhsh, Z. Grasley, B. Tyson, and R. K. Abu Al-Rub, "Dispersion quantification of inclusions in composites," Composites Part A: Applied Science and Manufacturing, vol. 42, no. 1, pp. 75-83, 2011.

[27] A. Sobolkina et al., "Dispersion of carbon nanotubes and its influence on the mechanical properties of the cement matrix," Cement and Concrete Composites, vol. 34, no. 10, pp. 1104-1113, 2012

[28] A. Al-Dahawi, O. Öztürk, F. Emami, G. Yıldırım, and M. Şahmaran, "Effect of mixing methods on the electrical properties of cementitious composites incorporating different carbon-based materials," Construction and Building Materials, vol. 104, pp. 160-168, 2016. 